DOI: 10.12731/2070-7568-2020-3-176-197

УДК 338.1

\title{
ФИНАНСОВОЕ СОСТОЯНИЕ РОССИЙСКИХ РЕГИОНОВ: ИНДИВИДУАЛИЗАЦИЯ УГРОЗ
}

\section{Пасынков А.Ф.}

Сочиально-экономическое развитие российских регионов крайне неоднородно, в настоящее время наблюдается сильная их дифференциация по различным параметрам. Одной из основных причин такого положения является значительный разрыв в регионах по уровню обеспеченности финансовыми ресурсами, предопределяя возможности региональных органов государственного и местного управления по регулированию угроз в социально-экономическом развитии территорий. В этих условиях оченка финансового состояния регионов и выявление возможных угроз в развитии становится актуальным в современных условиях нарастания кризисных явлений.

Цель исследования - определить возможные угрозы социильноэкономическому развитию регионов посредством оченки состояния финансовой сферы.

Методы исследования: в работе использованы методы общенаучного анализа и сопоставления, применены математические методы ранжирования регионов на основе средних значений. При выделении угроз финансовому развитию регионов применены методы обобщения и группировки.

Результаты: систематизированы факторы и индикаторы угроз, возникающих в финансовой сфере региона, характеризующиче изменения в социально-экономическом развитии территории. Проведена типология российских регионов по уровню развития финансовой сферы, выделены три типа регионов по уровню развития финансовой сферы. Для каждого из типов регионов вылелены наиболее явные угрозы в финансовой сфере в условиях ухудшения экономической ситуации. 
Область применения результатов: полученные результаты могут быть использованы в работе органов государственной власти при определении последствий финансовых кризисов для конкретных территорий или групп регионов.

Ключевые слова: регионы РФ; финансовая система; экономическая нестабильность; региональный бюджет.

\section{FINANCIAL STATE OF RUSSIAN REGIONS: INDIVIDUALIZATION OF THREATS}

\section{Pasynkov A.F.}

The socio-economic development of Russian regions is extremely heterogeneous; at present, there is a strong differentiation of them according to various parameters. One of the main reasons for this situation is a significant gap in the regions in terms of the level of financial resources, predetermining the capabilities of regional state and local government bodies to regulate threats in the socio-economic development of territories. Under these conditions, the assessment of the financial condition of the regions and the identification of possible threats to development becomes relevant in the modern conditions of the growing crisis.

The purpose of the study is to identify possible threats to the socio-economic development of regions by assessing the state of the financial sector.

Research methods: the work uses the methods of general scientific analysis and comparison, applied mathematical methods for ranking regions based on average values. When identifying threats to the financial development of regions, the methods of generalization and grouping were applied.

Results: the factors and indicators of threats arising in the financial sphere of the region, characterizing changes in the socio-economic development of the territory, have been systematized. A typology of Russian regions according to the level of development of the financial sphere is carried out, three types of regions are identified according to the level of development of the financial sphere. For each of the types of regions, 
the most obvious threats in the financial sphere in the context of a worsening economic situation are identified.

Keywords: regions of the Russian Federation; financial system; economic instability; regional budget.

\section{Введение}

В современных условиях функционирования рыночной экономики немаловажное место занимает финансовая система государства, являющаяся «кровеносной системой» экономического развития, обеспечивая формирование, распределение и использование ресурсов экономических агентов. Даже в условиях больших потрясений и социальных катастроф, финансовая система сохраняет свое важное значение в жизни государственной системы, обеспечивая возможность обмена и распределения товаров и ресурсов между предприятиями и населением, что в полной мере подтверждается историческими фактами в периоды сильных потрясений в России и за рубежом. Именно поэтому анализ и прогнозирование финансовой сферы при нарастании угроз различного характера является важной частью данного исследования.

Рассматривая региональный уровень развития финансовой сферы, необходимо в первую очередь отметить, что определяющим воздействием на параметры ее функционирования выступают макроэкономические параметры, то есть страновые условия, сформированные федеральными органами власти. В Российской Федерации, в условиях достаточно высокой централизации многих сфер деятельности, в том числе и финансовой, невозможно рассматривать финансовое развитие региона без влияния федеральной политики на распределение денежных потоков. Ярким примером выступает политика выравнивания доходов региональных бюджетов, направленная на сглаживание неравенства бюджетной обеспеченности территорий, с целью формирования более или менее равных условий предоставления социальных услуг в разных субъектах РФ.

С другой стороны, огромное разнообразие экономического потенциала российских регионов, специфика их развития, отрасле- 
вая направленность производства позволяют говорить о высокой дифференциации между регионами в финансовой области, которые отражаются в различных сферах деятельности регионов: бюджете, доходах населения, объемах производства и т.д. Такое разнообразие может отражаться или в некоторых направлениях финансовой деятельности (яркий пример - концентрация банковских и страховых услуг в г. Москва), либо проявляться во всех показателях деятельности региона, поскольку наполнение значительной части финансовых индикаторов достаточно сильно коррелируют между собой.

Поэтому, при нарастании угроз внутреннего и внешнего характера, характеристики развития финансовой сферы для разных регионов будут существенно отличаться, в зависимости от специфики территории, вовлеченности в явления кризисного характера, способностью экономики региона приспособиться к возникшим угрозам и т.д.

\section{Состояние вопроса}

В современной научной литературе вопросы состояния финансовой сферы регионов рассматривается в рамках общего социально-экономического развития территорий, часто не выделяя данную сферу в отдельный блок .

Наиболее популярный подход к оценке социально-экономического развития регионов РФ заключается в развитии форм расчета методики Минэкономразвития «Комплексная оценка уровня социально-экономического развития региона», включающей в себя 15 индикаторов социального и экономического развития региона. Так, в работе [1] проводится анализ данных показателей и авторы предлагают свой вариант оценки, на основе корреляционно-регрессионного анализа. В другой работе [2] для оценки социально-экономического развития региона использовались все те же 15 показателей, однако сгруппированные в четыре подгруппы и рассматриваемые в трехлетний период. Для оценки была применена методика по нахождению «Z-показателя», однако в итоге были получены схожие результаты. На наш взгляд, несмотря на применение экономико-ма- 
тематических методов, использование данного набора показателей в исследованиях социально-экономического развития регионов РФ закономерно приводит к одинаковым результатам, поскольку любые расчеты основываются на отклонениях от средних параметров.

Другим направлением оценки социально-экономического развития выступает увеличение числа анализируемых показателей с применением оригинальных моделей. Обширный обзор таких методик к оценке социально-экономического развития регионов приведен в работе [3]. Статья носит больше обзорный характер, в ней отсутствует авторский подход к оценке. Также, обзор методического инструментария оценки результативности социально-экономической политики развития регионов предложен в статье [4]. Здесь же разработана авторская методика оценки результативности социально-экономической политики развития регионов, составлена матрица определения типа регионов-реципиентов Центрального федерального округа. Предложенная методика является расширенной вариацией подхода к оценке социальных и экономических параметров, а оценка доноров и реципиентов основывается лишь на доле собственных доходов бюджета, что достаточно узко. В другом исследовании О.В. Глушакова, Я.А. Вайсберг [5], предложена методика оценки уровня и направленности развития социального и экономического пространства регионов, где несколько увеличен перечень показателей оценки. Проведено разделение расчетов индексов социального и экономического развития, затем для них находится среднее значение. Применение такого подхода, конечно, более корректно, однако в итоге социальное и экономическое развитие все равно учитывается в равной степени. Значительно расширены блоки показателей при оценке социально-экономического положения региона в работе [6], предлагается выделить индексы развития социально-экономической подсистемы, экологической подсистемы и социально-культурной подсистемы. Однако в исследовании, несмотря на приведенные расчеты автора для регионов Северо-Запада, не приведен список показателей, используемых для оценки подсистем, что не позволяет в полной мере оценить адекватность модели. По- 
строение достаточно сложной математической модели для расчета интегрального показателя проведено в исследовании [7]. В то же время, работа больше посвящена математическому описанию модели и фокусировки ее применения на примере Республики Крым, а состав анализируемых показателей не раскрывается. В этом же журнале представлена работа А.Э. Калинина, А.Ф. Соколова [8], где авторами предложена методика определения эффективности управления экономикой региона на основе интегральной оценки объекта и субъекта региональной системы управления. Фактически, к общераспространенной методике социально-экономического развития были добавлены блоки по эффективности деятельности органов государственной власти (например, численность чиновников, состояние информационной инфраструктуры и т.д.), что достаточно спорно с точки зрения оценки регионов. В другой работе [9] автор представил методический подход к оценке уровня социально-экономического развития региона на основе экономико-математической модели управления развитием территорий. Несмотря на представленные в работе формулы на основе функции Коббла-Дугласа, отсутствие конкретных расчетов не позволяет оценить эффективность предложенного методического подхода.

К другой группе исследований можно отнести работы, где оценка социально-экономического развития региона выступает этапом прогнозирования его дальнейшего развития. Например, проблемы определения эффективности реализации стратегии развития региона исследует Балакина Г.Ф. [10]. Автором предложена методика сравнительной оценки результативности реализации возможных (альтернативных) стратегий развития региона, а также алгоритм определения показателя эффективности на основе индикатора мультипликативного экономического эффекта и экспертных оценок. Данный подход использован при формировании возможных стратегий развития Республики Тыва до 2020 г. Анализ социально-экономического развития российских регионов с позиции прогнозирования трендов их развития рассматривается в статье [11]. Основной вывод исследования заключается в том, что согласно расчетам авторов, в 
2011-2015 гг. преобладали регионы страны, характеризующиеся низким и ниже среднего уровнем социально-экономического развития, с совокупной долей порядка $64,3 \%$. Отметим, что набор и количество показателей в данных работах варьируется в зависимости от целей прогнозирования, однако в данных работах используется тот же принцип ранжирования регионов.

На уровне муниципальных образований в современной литературе используются примерно такие же подходы. Так, пермскими специалистами исследуются особенности оценки социально-экономического развития сельских территорий [12], где основным отличием выступает необходимость учета государственных программ и проектов по развитию сельского хозяйства. В продолжение муниципальной тематики можно упомянуть работу Е.С . Губановой, В.С. Клещ [13], которые предложили рассматривать неравномерность социально-экономического развития как процесс, который проходит в своем изменении три стадии: дифференциация, асимметрия, поляризация. Также авторами была предложена методика оценки уровня неравномерности развития региона, которая позволяет установить «вклад» каждого района в исследуемый процесс. По набору показателей и методам расчета данная методика практически идентична применяемым походам на региональном уровне.

С другой стороны, в отечественной литературе существует мнение, что оценка развития регионов должна основываться не только на сравнительной характеристике определенных параметров, но и учитывать его динамику в сравнении, как с региональным, так и общероссийским развитием показателей [14-20]. Данный поход реализуется в виде оценки лишь финансовых параметров развития регионов и муниципальных образований, оставляя за скобками социальные и прочие показатели. В качестве основных показателей, описывающих уровень экономического развития регионов, в данных работах используются показатели Системы национальных счетов, на основе которых формируются финансовые балансы.

На наш взгляд, использование последнего подхода наиболее корректно при определении финансового состояния территорий, по- 
скольку необходимо оценивать конкретную сферу территории отдельно (экономическую, финансовую, социальную, экологическую и т.д.), для получения объективного результата.

\section{Материалы и методы исследования}

Анализ финансового состояния российских регионов, на наш взгляд, должен отображать оценку различных сторон экономического развития территорий. В этом случае необходимо оценивать не только бюджет и его составляющие, но и денежные потоки домашних хозяйств, предприятий и т.д.

С теоретической точки зрения, финансовые средства (потоки) первично зарождаются в сфере производства и оказания услуг, часть средств перераспределяются через бюджет, а затем используются на конечное потребление населением. Именно такие постулаты используются при расчете эффективности деятельности территорий, в том числе и национальном счетоводстве [21].

Поэтому нами предлагается использовать набор индикаторов для отображения состояния финансовой сферы региона, который мог бы охватить все сферы обращения финансовых потоков. Несмотря на большое разнообразие показателей, характеризующих финансовую сферу территории, на взгляд автора, для общей оценки уровня финансового состояния достаточно проведения анализа ряда укрупненных показателей, отображающих ключевые элементы развития финансовой сферы, и позволяющих определить угрозы для регионов, в частности:

1. Показатели, характеризующие уровень функционирования экономической сферы региона:

- валовой региональный продукт на душу населения, характеризующий уровень экономического развития региона;

- доля инвестиций в основной капитал в ВРП региона, показывающий перспективы дальнейшего развития экономической сферы.

2. Показатели, характеризующие бюджетную обеспеченность региона: 
- доля собственных доходов в общем объеме доходов регионального бюджета, обеспечивает устойчивость бюджетной системы;

- уровень бюджетной обеспеченности на жителя региона, необходим для оценки возможностей бюджета в случае нарастания угроз.

3. Показатели, характеризующие уровень жизни населения региона:

- средняя заработная плата работников, классический индикатор уровня жизни наемных работников;

- расходы бюджета на социальную поддержку, как производный показатель эффективности поддержки незащищенных групп населения.

В этой связи нами предлагается использовать набор индикаторов для отображения состояния финансовой сферы региона, в которые входят и бюджетные расходы, инвестиции, заработная плата работников, оценка добавленной стоимости (ВРП) и т.д. Оценка финансового состояния в предлагаемой нами методике осуществляется в соответствии с общепринятом в последнее время принципом «светофора». То есть наивысшим значениям конкретного региона по определенному показателю присваивается зеленый цвет, средним значениям - желтый, а для низких значений используется красный цвет. Критерии оценки сформированы исходя из аналитической выборки диапазонов «нормальности» и выглядят для финансовой сферы следующим образом:

- высокий уровень (зеленая зона)

- средний уровень (желтая зона)

- низкий уровень (красная зона)

$$
\begin{aligned}
& \text { выше }\left(\bar{x}+\frac{\sigma}{2}\right) \\
& \text { от }\left(\bar{x}-\frac{\sigma}{2}\right) \text { до }\left(\bar{x}+\frac{\sigma}{2}\right) \\
& \text { ниже }\left(\bar{x}-\frac{\sigma}{2}\right)
\end{aligned}
$$

где $\bar{x}$ - среднее значение показателя по всей совокупности регионов, $\sigma-$ среднее квадратическое отклонение показателя по всей совокупности регионов.

Общий индекс развития финансовой сферы регионов РФ рассчитывается мна основе придания значений каждому из индикаторов по схеме: ниже среднего - 0 , средний уровень -1 , высокий 
уровень - 2. Затем находится среднее арифметическое значение по индикаторам для каждого региона, и рассчитываются диапазоны общего развития финансовой сферы по той же методологии. В итоге был сформирован интегральная типология регионов по уровню развития финансовой сферы (таблица 1).

На этой основе автором были выделены основные угрозы функционирования финансовой сферы региона, исходя из возможного ухудшения каждого из рассчитываемых индикаторов (таблица 2).

Таблица 2.

Угрозы функционирования финансовой сферы регионов

\begin{tabular}{|c|c|c|}
\hline Факторы & Угрозы & Индикаторы \\
\hline $\begin{array}{l}\text { Ухудшение } \\
\text { экономической } \\
\text { активности в регионе }\end{array}$ & $\begin{array}{l}\text { Увеличение нагрузки на } \\
\text { федеральный бюджет и } \\
\text { регионы-доноры }\end{array}$ & $\begin{array}{l}\text { Валовой региональный } \\
\text { продукт (ВРП) на душу } \\
\text { населения, тыс. }\end{array}$ \\
\hline $\begin{array}{l}\text { Снижение } \\
\text { инвестиционной } \\
\text { активности } \\
\text { организаций региона }\end{array}$ & $\begin{array}{l}\text { Ухудшение финансового } \\
\text { и экономического } \\
\text { состояния в будущем } \\
\text { периоде }\end{array}$ & $\begin{array}{l}\text { Доля инвестиций в } \\
\text { основной капитал в ВРП, \% }\end{array}$ \\
\hline $\begin{array}{l}\text { Изменения расходов } \\
\text { консолидированного } \\
\text { бюджета региона }\end{array}$ & $\begin{array}{l}\text { Недостаток средств } \\
\text { для выполнения } \\
\text { обязательств } \\
\text { регионального } \\
\text { правительства }\end{array}$ & $\begin{array}{l}\text { Уровень бюджетной } \\
\text { обеспеченности по } \\
\text { расходам, тыс. руб. на } \\
\text { жителя }\end{array}$ \\
\hline $\begin{array}{l}\text { Волатильность } \\
\text { в формировании } \\
\text { собственных доходов } \\
\text { регионального бюджета }\end{array}$ & $\begin{array}{l}\text { Снижение } \\
\text { самостоятельности } \\
\text { бюджетов территорий }\end{array}$ & $\begin{array}{l}\text { Доля собственных } \\
\text { доходов в доходах } \\
\text { консолидированного } \\
\text { бюджета, \% }\end{array}$ \\
\hline $\begin{array}{l}\text { Социальная } \\
\text { ориентация расходов } \\
\text { региональных } \\
\text { бюджетов }\end{array}$ & $\begin{array}{l}\text { Снижение социальной } \\
\text { защищенности } \\
\text { отдельных категорий } \\
\text { граждан }\end{array}$ & $\begin{array}{l}\text { Расходы } \\
\text { консолидированных } \\
\text { бюджетов на реализацию } \\
\text { мер социальной поддержки } \\
\text { отдельных категорий } \\
\text { граждан, в \% от расходов }\end{array}$ \\
\hline $\begin{array}{l}\text { Изменения денежных } \\
\text { доходов населения }\end{array}$ & $\begin{array}{l}\text { Снижение доходов } \\
\text { консолидированного } \\
\text { бюджетов регионов, } \\
\text { повышение расходов на } \\
\text { социальные выплаты }\end{array}$ & $\begin{array}{l}\text { Среднемесячная } \\
\text { номинальная начисленная } \\
\text { заработная плата работников } \\
\text { организаций по Российской } \\
\text { Федерации, тыс. руб. }\end{array}$ \\
\hline
\end{tabular}

Как видно из таблицы, основные угрозы в финансовой сфере региона определяются не только бюджетными возможностями территорий, но и деятельностью предприятий и населения. Конечно, 
данные индикаторы и угрозы взаимосвязаны, например ухудшение общеэкономической обстановки в стране оказывает влияние как на предприятия, так и население, что в свою очередь приводит к снижению доходов бюджета региона. В то же время, регулирование бюджетных доходов со стороны федеральных органов власти может снизить угрозы для бюджета региона, также положительно влияя на доходы домашних хозяйств и финансовое благополучие предприятий региона.

\section{Результаты и их обсуждение}

В итоге, проведенные расчеты по финансовому состоянию российских регионов позволили нам сформировать три группы регионов по уровню развития финансовой сферы. К тому же были проанализированы и выделены основные риски и угрозы отдельным группам регионов в финансовой сфере, в результате чего в каждой из групп мы смогли выделить подгруппы, в зависимости от возникающих угроз. Данные представлены в таблице 3.

К группе с низким уровнем развития финансовой сферь относятся 27 регионов. Наихудшая ситуация в финансовой сфере регистрируется в республиках Северного Кавказа, практически по всем индикаторам в данных регионах, поэтому основной угрозой для данной группы выступает снижение трансфертов из федерального бюджета. Другая подгруппа данной группы характеризуется снижением промышленного потенциала, и нарастание этой тенденции представляет наибольшую опасность для данных регионов. Для третьей подгруппы, которая находится на грани «нормальности», основной угрозой является снижение бюджетного потенциала и ухудшение показателей ВРП.

$K$ группе со средним уровнем развития финансовой сферы относится 36 регионов. Здесь выделяются две основные подгруппы, связанные с динамикой отдельных индикаторов. Первая подгруппа, у которой индикаторы указывают на ухудшение показателей по сравнению со среднероссийскими, основными угрозами выступают замедление экономического развития, что может привести к переходу в группу с низким уровнем развития. Вторая подгруппа, с до- 
статочно хорошими финансовыми индикаторами, как риск можно выделить ухудшение инвестиционной активности субъектов хозяйственной деятельности, что может неблагоприятно сказаться на дальнейшем развитии и потери устойчивости.

В группу с высоким уровнем развития финансовой сферы входят 20 регионов. Это наиболее финансово благополучные регионы в России. Однако их благополучие основано на различных факторах и условиях. Первая подгруппа регионов характеризуется диверсифицированной структурой экономики, стабильными значениями индикаторов, поэтому явных угроз в их развитии не наблюдается. Вторую подгруппу, столичные города, Москва и Санкт-Петербург, в финансовом плане выделяют особо, поскольку в них сконцентрированы значительные потоки из всей России, и потеря данного статуса и представляет собой угрозу для данных регионов. Последняя подгруппа, как правило, это регионы с высокой добавленной стоимостью, экономика которых основана на добыче полезных ископаемых, в настоящее время являются образцом финансового благополучия. В то же время при нарастании неблагоприятных тенденций на мировых товарных рынках, угрозу представляет резкое сокращение доходов всех субъектов экономики, что неблагоприятно скажется на выполнении обязательств региональной казны.

Таблица 3.

Типология регионов по уровню развития финансовой сферы регионов

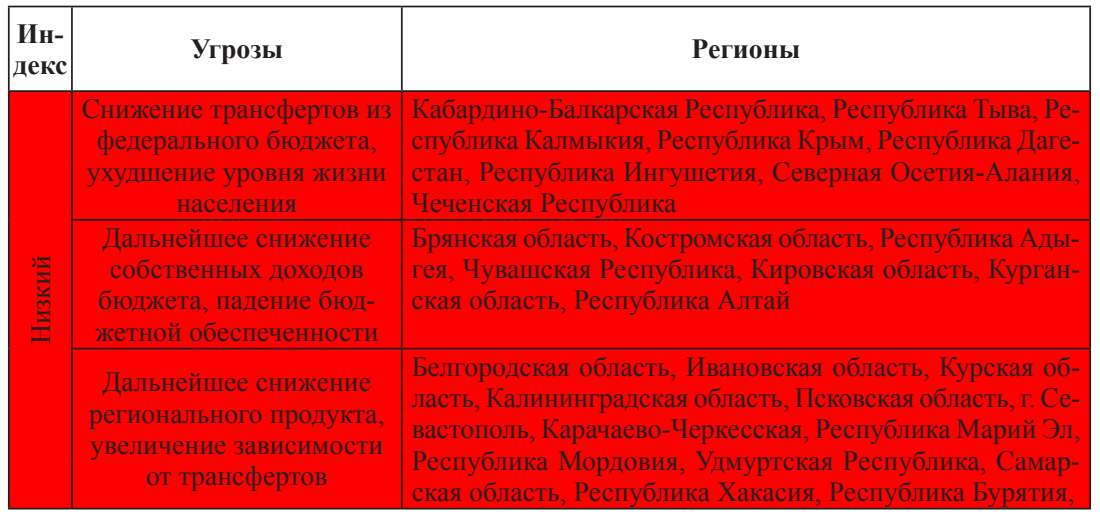


Окончание табл. 3.

\begin{tabular}{|c|c|c|}
\hline \multirow[b]{2}{*}{ 仓े } & $\begin{array}{c}\text { Снижение собственных } \\
\text { доходов бюджета, сниже- } \\
\text { ние уровня заработных } \\
\text { плат }\end{array}$ & $\begin{array}{l}\text { Орловская область, Рязанская область, Тамбовская об- } \\
\text { ласть, Ростовская область, Ставропольский край, Респу- } \\
\text { блика Башкортостан, Республика Татарстан, Нижегород- } \\
\text { ская область, Пензенская область, Ульяновская область, } \\
\text { Челябинская область, Алтайский край, Новосибирская } \\
\text { область, Омская область, Приморский край }\end{array}$ \\
\hline & $\begin{array}{l}\text { Потеря инвестиций в } \\
\text { основной капитал, сни- } \\
\text { жение ВРП на душу на- } \\
\text { селения }\end{array}$ & $\begin{array}{l}\text { Владимирская область, Калужская область, Липецкая об- } \\
\text { ласть, Смоленская область, Тверская область, Тульская } \\
\text { область, Ярославская область, Республика Карелия, Ле- } \\
\text { нинградская область, Краснодарский край, Астраханская } \\
\text { область, Волгоградская область, Пермский край, Орен- } \\
\text { бургская область, Саратовская область, Свердловская об- } \\
\text { ласть, Иркутская область, Кемеровская область, Томская } \\
\text { область, Забайкальский край, Камчатский край }\end{array}$ \\
\hline \multirow{3}{*}{ 罚 } & $\begin{array}{c}\text { Диверсифицированные } \\
\text { экономики, угрозы не вы- } \\
\text { являются }\end{array}$ & $\begin{array}{l}\text { Воронежская область, Московская область, Вологодская } \\
\text { область, Новгородская область, Красноярский край, Ха- } \\
\text { баровский край, Амурская область, Еврейская автоном- } \\
\text { ная область }\end{array}$ \\
\hline & $\begin{array}{c}\text { Потеря столичного статуса, } \\
\text { резкое снижение финансо- } \\
\text { вой самостоятельности }\end{array}$ & г. Санкт-Петербург, г. Москва, \\
\hline & $\begin{array}{l}\text { Ухудшение конъюнкту- } \\
\text { ры на сырье на внешних } \\
\text { рынках, снижение из- } \\
\text { быточности финансовых } \\
\text { ресурсов }\end{array}$ & $\begin{array}{l}\text { Чукотский автономный округ, Республика Коми, Архан- } \\
\text { гельская область (в т.ч. Ненецкий автономный округ), } \\
\text { Мурманская область, Тюменская область (в т.ч. Хант-- } \\
\text { Мансийский автономный округ, Ямало-Ненецкий авто-- } \\
\text { номный округ), Магаданская область, Сахалинская об- } \\
\text { ласть, Республика Саха (Якутия) }\end{array}$ \\
\hline
\end{tabular}

\section{Заключение}

В целом, проведенное исследование позволило сделать ряд основных выводов по финансовому состоянию российских регионов и возможных угроз его развитию.

1) Наиболее благополучное финансовое состояние демонстрируют группы регионов, экономика которых базируется на добыче природных ресурсов, либо имеющих административную ренту. Соответственно, основной угрозой для потери такого состояния является потеря таких преимуществ, что в современных кризисных условиях выглядит достаточно вероятным.

2) Для ряда регионов, входящих в группу с высоким уровнем финансовой сферы, имеющих диверсифицированную экономику, мы не смогли выделить явные угрозы в финансовом развитии, и эта подгруппа регионов достаточно пестрая, в нее входят даже несколько регионов Дальнего Востока. 
3) Большинство регионов России относятся к группе со средним уровнем развития финансовой сферы, это практически все регионы центральной России, Урала и Дальнего Востока. Данная группа регионов имеет достаточно большие риски, как по ухудшению финансового состояния, так и его улучшения. Поскольку достаточно незначительное изменение показателей из любой сферы для перемещения регионов в красную либо зеленую зону.

4) Группа регионов с низкими уровнем развития финансовой сферы демонстрирует высокую зависимость от трансфертов из федерального бюджета, что, в отсутствии крупной промышленности, оказывает решающее влияние на все сферы регионов.

5) Наихудшее положение по уровню развития финансовой сферы сложилось в регионах Северного Кавказа и ряде других регионов, и вероятность улучшения их финансового положения крайне низка.

Благодарность. Публикация подготовлена в соответствие с государственным заданием для ФГБУН Института экономики УрО РАН на 2020-2022 гг.

Таблица 1.

Значения и рейтинг показателей, позволяющих оценить риски и угрозы функционирования финансовой сферы регионов, 2018 г.

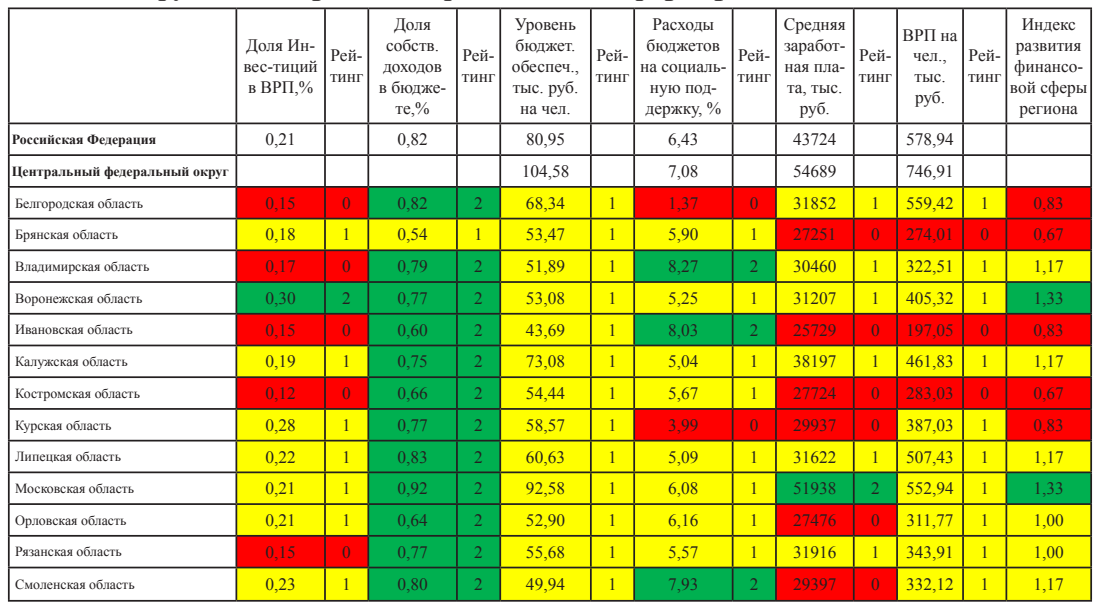




\begin{tabular}{|c|c|c|c|c|c|c|c|c|c|c|c|c|c|}
\hline & & & & & & & & & & \multicolumn{4}{|c|}{ Продолжение табл. I } \\
\hline Тамбовская область & 0,28 & 1 & 0,61 & 2 & 52,56 & 1 & 7,11 & 1 & 26660 & 0 & 326,41 & 1 & 1,00 \\
\hline Тверская область & 0,24 & 1 & 0,84 & 2 & 52,51 & 1 & 7,00 & 1 & 31049 & 1 & 347,76 & 1 & 1,17 \\
\hline Тульская область & 0,24 & 1 & 0,83 & 2 & 60,28 & 1 & 7,06 & 1 & 34662 & 1 & 430,11 & 1 & 1,17 \\
\hline Ярославская область & 0,14 & 0 & 0,87 & 2 & 64,16 & 1 & 8,42 & 2 & 33474 & 1 & 444,90 & 1 & 1,17 \\
\hline г.Москва & 0,14 & 0 & 0,97 & 2 & 184,33 & 2 & 7,95 & 2 & 83801 & 2 & 1417,48 & 2 & 1,67 \\
\hline $\begin{array}{l}\text { Северо--аападный федераль- } \\
\text { ный округ }\end{array}$ & & & 0,85 & & 95,55 & & 6,72 & & 49824 & & 645,23 & & \\
\hline Республика Карелия & 0,15 & 0 & 0,62 & 2 & 81,30 & 1 & 10,00 & 2 & 39402 & 1 & 453,09 & 1 & 1,17 \\
\hline Республика Коми & 0,19 & 1 & 0,91 & 2 & 103,05 & 1 & 6,18 & 1 & 50413 & 2 & 802,09 & 2 & 1,50 \\
\hline Архангельская область & 0,23 & 1 & 0,79 & 2 & 78,61 & 1 & 9,79 & 2 & 48307 & 2 & 716,13 & 2 & 1,67 \\
\hline в т.ч. Ненецкий автономный округ & 0,30 & 2 & 0,92 & 2 & 486,9 & 2 & 10,10 & 2 & 82786 & 2 & 6936,67 & 2 & 2,00 \\
\hline Вологодская область & 0,26 & 1 & 0,87 & 2 & 63,86 & 1 & 10,89 & 2 & 35497 & 1 & 498,83 & 1 & 1,33 \\
\hline Калининградская область & 0,28 & 1 & 0,40 & 1 & 123,73 & 1 & 2,73 & 0 & 33385 & 1 & 459,94 & 1 & 0,83 \\
\hline Ленинградская область & 0,42 & 2 & 0,93 & 2 & 83,41 & 1 & 4,47 & 0 & 43631 & 1 & 597,64 & 1 & 1,17 \\
\hline Мурманская область & 0,30 & 2 & 0,89 & 2 & 110,04 & 1 & 9,43 & 2 & 58045 & 2 & 645,12 & 1 & 1,67 \\
\hline Новгородская область & 0,23 & 1 & 0,76 & 2 & 61,67 & 1 & 7,60 & 2 & 31462 & 1 & 436,68 & 1 & 1,33 \\
\hline Псковская область & 0,19 & 1 & 0,62 & 2 & 57,40 & 1 & 5,09 & 1 & 0 & 0 & 260.68 & 0 & 0,83 \\
\hline r.Санкт-Петербург & 0,18 & 0 & 0,96 & 2 & 107,67 & 1 & 6,87 & 1 & 60421 & 2 & 778,88 & 2 & 1,33 \\
\hline Южный федеральный округ & & & 0,70 & & 56,36 & & 6,04 & & 31998 & & 355,45 & & \\
\hline Республика Адыгея & 0,29 & 2 & 0,57 & 1 & 51,17 & 1 & 4,20 & 0 & 27469 & 0 & 238,28 & 0 & 0,67 \\
\hline Республика Калмыкия & 0,18 & 0 & 0,55 & 1 & 56,23 & 1 & 6,57 & 1 & 26049 & 0 & 270,93 & 0 & 0,50 \\
\hline Республика Крым & 0,76 & 2 & 0,31 & 0 & 91,77 & 1 & 4,42 & 0 & 29640 & 0 & 204,65 & 0 & 0,50 \\
\hline Краснодарский край & 0,21 & 1 & 0,87 & 2 & 53,18 & 1 & 6,51 & 1 & 33846 & 1 & 415,12 & 1 & 1,17 \\
\hline Астраханская область & 0,19 & 1 & 0,77 & 2 & 48,12 & 1 & 6,47 & 1 & 33630 & 1 & 545,76 & 1 & 1,17 \\
\hline Волгоградская область & 0,22 & 1 & 0,76 & 2 & 47,48 & 1 & 6,49 & 1 & 30894 & 1 & 339,72 & 1 & 1,17 \\
\hline Ростовская об̆ласть & 0,17 & 0 & 0,82 & 2 & 49,83 & 1 & 6,94 & 1 & 31448 & 1 & 344,09 & 1 & 1,00 \\
\hline г.Севастополь & 0,51 & 2 & 0,35 & 1 & 80,62 & 1 & 3,60 & 0 & 31814 & 1 & 178,90 & 0 & 0,83 \\
\hline $\begin{array}{l}\text { Северо-Кавказский } \\
\text { федеральный округ }\end{array}$ & & & 0,42 & & 43,21 & & 4,33 & & 27064 & & 196,80 & & \\
\hline Республика Дагестан & 0,32 & 2 & 0,33 & 1 & 34,98 & 0 & 1,43 & 0 & 25155 & 0 & 202,55 & 0 & 0.50 \\
\hline Республика Ингушетия & 0,40 & 2 & 0,21 & 0 & 49,22 & 1 & 2,10 & 0 & 25367 & 0 & 111,36 & 0 & 0.50 \\
\hline Кабардино-Балкарская & 0,24 & 1 & 0,46 & 1 & 39.41 & 0 & 4,38 & 0 & 25776 & 0 & 168,20 & 0 & 0,33 \\
\hline Карачаево-Черкесская . & 0,32 & 2 & 0,33 & 1 & 56,74 & 1 & 5,88 & 1 & 25430 & 0 & 165.34 & 0 & 0,83 \\
\hline Северная Осетия-Алания & 0,25 & 1 & 0,48 & 1 & 46,61 & 1 & 3,14 & 0 & 26958 & 0 & 186,04 & 0 & 0,50 \\
\hline Чеченская Республика & 0,40 & 2 & 0,20 & 0 & 55,26 & 1 & 2,86 & 0 & 26177 & 0 & 132,52 & 0 & 0,50 \\
\hline Ставропольский край & 0,22 & 1 & 0,67 & 2 & 43,02 & 1 & 8,35 & 2 & 29065 & 0 & 256,00 & 0 & 1,00 \\
\hline Приволжский федеральный округ & & & 0,82 & & 56,78 & & 6,08 & & 31990 & & 424,11 & & \\
\hline Республика Башкортостан & 0,16 & 0 & 0,83 & 2 & 53,14 & 1 & 6,28 & 1 & 33753 & 1 & 413,16 & 1 & 1,00 \\
\hline Республлика Марий Эл & 0,16 & 0 & 0,64 & 2 & 44,76 & 1 & 9,25 & 2 & 28143 & 0 & 260,98 & 0 & 0,83 \\
\hline Республлика Мордовия & 0,23 & 1 & 0,70 & 2 & 60,62 & 1 & 5,04 & 1 & 26712 & 0 & 285,90 & 0 & 0,83 \\
\hline Республика Татарстан & 0,26 & 1 & 0,87 & 2 & 81,92 & 1 & 3,72 & 0 & 35172 & 1 & 633,30 & 1 & 1,00 \\
\hline Удмуртская Респуб̆лика & 0,16 & 0 & 0,79 & 2 & 55,56 & 1 & 0.65 & 0 & 31808 & 1 & 418,79 & 1 & 0,83 \\
\hline Чувашская Республика & 0,17 & 0 & 0,66 & 2 & 45,63 & 1 & 6,32 & 1 & 27036 & 0 & 243,48 & 0 & 0,67 \\
\hline Пермский край & 0,18 & 1 & 0,89 & 2 & 58,74 & 1 & 7,11 & 1 & 35802 & 1 & 504,97 & 1 & 1,17 \\
\hline Кировская область & 0,17 & 0 & 0,67 & 2 & 49,30 & 1 & 7,23 & 1 & 27932 & 0 & 261,44 & 0 & 0.67 \\
\hline Нижегородская область & 0,19 & 1 & 0,87 & 2 & 57,92 & 1 & 3,85 & 0 & 32949 & 1 & 425,36 & 1 & 1,00 \\
\hline Оренбургская область & 0,20 & 1 & 0,84 & 2 & 49,21 & 1 & 6,56 & 1 & 30371 & 1 & 509,75 & 1 & 1,17 \\
\hline Пензенская область & 0,22 & 1 & 0,67 & 2 & 49,04 & 1 & 7,01 & 1 & 28968 & 0 & 303,88 & 1 & 1,00 \\
\hline Самарская область & 0,17 & 0 & 0,42 & 1 & 57,32 & 1 & 7,24 & 1 & 33754 & 1 & 474,56 & 1 & 0,83 \\
\hline Саратовская область & 0,22 & 1 & 1,63 & 2 & 43,11 & 1 & 8,15 & 2 & 26823 & 0 & 291,91 & 1 & 1,17 \\
\hline Ульяновская область & 0,23 & 1 & 0,81 & 2 & 52,46 & 1 & 10,25 & 2 & 28353 & 0 & 280,98 & 0 & 1,00 \\
\hline
\end{tabular}




\begin{tabular}{|c|c|c|c|c|c|c|c|c|c|c|c|c|c|}
\hline Уральский федеральный округ & & & 0,91 & & 96,82 & & 6,55 & & 47807 & & 1032,78 & & \\
\hline Курганская область & 0,13 & 0 & 0,54 & 1 & 55,00 & 1 & 8,48 & 2 & 28159 & 0 & 255,13 & 0 & 0,67 \\
\hline Свердловская область & 0,14 & 0 & 0,92 & 2 & 67,66 & 1 & 9,61 & 2 & 38052 & 1 & 527,71 & 1 & 1,17 \\
\hline Тюменская область & 0,26 & 1 & 0,96 & 2 & 51,38 & 1 & 17,60 & 2 & 68664 & 2 & 2361,12 & 2 & 1,67 \\
\hline $\begin{array}{l}\text { в чч. Ханты-Мансийский автоном- } \\
\text { ный округ }\end{array}$ & 0,21 & 1 & 0,95 & 2 & 170,31 & 2 & 7,06 & 1 & 70896 & 2 & 2672,76 & 2 & 1,67 \\
\hline Ямало-Ненецкий автономный округ & 0,33 & 2 & 0,92 & 2 & 350,06 & 2 & 4,42 & 0 & 97204 & 2 & 5699,71 & 2 & 1,67 \\
\hline Челябинская область & 0,18 & 0 & 0,86 & 2 & 55,73 & 1 & 6,56 & 1 & 35219 & 1 & 423,97 & 1 & 1,00 \\
\hline Сибирский федеральный округ & & & 0,79 & & 68,37 & & 6,08 & & 37807 & & 485,21 & & \\
\hline Республика Алтай & 0,29 & 1 & 0,33 & 1 & 95,76 & 1 & 4,57 & 0 & 30953 & 1 & 230,90 & 0 & 0,67 \\
\hline Респуб̆лика Тыва & 0,15 & 0 & 0,21 & 0 & 89,68 & 1 & 3,51 & 0 & 35779 & 1 & 212,27 & 0 & 0,33 \\
\hline Республика Хакасия & 0,14 & 0 & 0,74 & 2 & 71,22 & 1 & 4,65 & 0 & 37874 & 1 & 438,20 & 1 & 0,83 \\
\hline Алтайский край & 0,20 & 1 & 0,60 & 2 & 47,57 & 1 & 9,17 & 2 & 25519 & 0 & 235,74 & 0 & 1,00 \\
\hline Красноярский край & 0,18 & 1 & 0,86 & 2 & 96,80 & 1 & 4,74 & 0 & 45635 & 2 & 793,33 & 2 & 1,33 \\
\hline Иркутская область & 0,23 & 1 & 0,87 & 2 & 75,08 & 1 & 5,29 & 1 & 42647 & 1 & 580,87 & 1 & 1,17 \\
\hline Кемеровская область & 0,21 & 1 & 0,84 & 2 & 62,82 & 1 & 6,41 & 1 & 38023 & 1 & 464,32 & 1 & 1,17 \\
\hline Новосибирская область & 0,16 & 0 & 0,86 & 2 & 62,37 & 1 & 7,10 & 1 & 35686 & 1 & 448,36 & 1 & 1,00 \\
\hline Омская область & 0,17 & 0 & 0,74 & 2 & 51,35 & 1 & 5,56 & 1 & 32613 & 1 & 350,63 & 1 & 1,00 \\
\hline Томская область & 0,16 & 0 & 0,83 & 2 & 69,32 & 1 & 8,14 & 2 & 41901 & 1 & 537,94 & 1 & 1,17 \\
\hline $\begin{array}{l}\text { Дальневосточный федераль- } \\
\text { ный округ }\end{array}$ & & & 0,69 & & & & & & & & & & \\
\hline Республика Бурятия & 0,22 & 1 & 0,53 & 1 & 66,28 & 1 & 5,19 & 1 & 36047 & 1 & 230,05 & 0 & 0,83 \\
\hline Республика Саха (Якутия) & 0,37 & 2 & 0,67 & 2 & 243,84 & 2 & 5,07 & 1 & 68871 & 2 & 1121,57 & 2 & 1,83 \\
\hline Забайкальский край & 0,28 & 1 & 0,62 & 2 & 66,06 & 1 & 5,32 & 1 & 40740 & 1 & 306,63 & 1 & 1,17 \\
\hline Камчатский край & 0,17 & 0 & 0,39 & 1 & 273,68 & 2 & 4.79 & 0 & 73896 & 2 & 750,74 & 2 & 1,17 \\
\hline Приморский край & 0,17 & 0 & 0,78 & 2 & 66,08 & 1 & 6,12 & 1 & 42199 & 1 & 438,50 & 1 & 1,00 \\
\hline Хабаровский край & 0,18 & 1 & 0,78 & 2 & 100,31 & 1 & 5,88 & 1 & 47153 & 2 & 537,96 & 1 & 1,33 \\
\hline Амурская область & 0,80 & 2 & 0,78 & 2 & 81,58 & 1 & 7,22 & 1 & 42315 & 1 & 379,18 & 1 & 1,33 \\
\hline Магаданская область & 0,30 & 2 & 0,64 & 2 & 275,86 & 2 & 3,67 & 0 & 85631 & 2 & 1210,80 & 2 & 1,67 \\
\hline Сахалинская область & 0,19 & 1 & 0,86 & 2 & 337,38 & 2 & 6,98 & 1 & 77499 & 2 & 2407,49 & 2 & 1,67 \\
\hline Еврейская автономная область & 0,30 & 2 & 0,66 & 2 & 76,30 & 1 & 5,62 & 1 & 39242 & 1 & 348,81 & 1 & 1,33 \\
\hline Чукотский автономный округ & 0,19 & 1 & 0,37 & 1 & 716,70 & 2 & 1,50 & 0 & 98864 & 2 & 1562,87 & 2 & 1,33 \\
\hline
\end{tabular}

\section{Список литературы}

1. Зеляк Е.Ф., Болдырева А.М. Оценка значимости показателей социально-экономического развития регионов РФ // Экономическая наука современной России. 2003. № 4. C. 48-53. URL: https://elibrary. ru/item.asp? $\mathrm{id}=9614460$.

2. Кислицына В.В., Чеглакова Л.С., Караулов В.М., Чикишева А.Н. Формирование комплексного подхода к оценке социально-экономического развития регионов // Экономика региона. 2017. Т. 13, вып. 2. C. 369-380. URL: https://elibrary.ru/item.asp?id=29364283. DOI:10.17059/2017-2-4

3. Скотаренко О.В. Российский опыт оценки уровня социально-экономического развития региона // Фундаментальные исследования. 2013. №1. C. 823-829. URL: https://elibrary.ru/item.asp?id=18771787. 
4. Меньщикова В.И., Черкашнев Р.Ю. Методический инструментарий оценки результативности социально-экономической политики развития регионов // Социально-экономические явления и процессы. 2013. № 3(49). C. 110-116. URL: https://elibrary.ru/item.asp?id=19084048.

5. Глушакова О.В., Вайсберг Я.А. Социальное и экономическое пространство регионов: концептуальные подходы к измерению и методика оценки (на примере регионов Сибирского федерального округа) // Вестник Томского государственного университета. Экономика. 2013. №2(22). C. 159-173. URL: https://elibrary.ru/item.asp?id=19371507.

6. Шабунова А.А., Груздева М.А. Развитие регионов Российской Федерации: интегральная методика как инструмент оценки // Региональная экономика: теория и практика. 2016. №1. С. 100-112. URL: https://elibrary.ru/item.asp?id=25239178.

7. Нижегородцев Р.М., Пискун Е.И., Кудревич В.В. Прогнозирование показателей социально-экономического развития региона // Экономика региона. 2017. T. 13, вып. 1. С. 38-48. URL: https://elibrary.ru/ item.asp?id=28807316. DOI: 10.17059/2017-1-4.

8. Калинина А.Э., Соколов А.Ф. Эффективность управления регионом в условиях модернизационных преобразований российской экономики и развития информатизации // Экономика региона. 2013. № 3. С. 112-121. URL: https://elibrary.ru/item.asp?id=20285472. DOI: 10.17059/2013-3-9.

9. Цомартова Л.В. Методика оценки уровня социально-экономического развития региона и модели управления экономическим развитием региона // Вестник Северо-Осетинского государственного университета имени Коста Левановича Хетагурова. 2010. № 3. С. 128-135. URL: https://elibrary.ru/item.asp?id=15237342.

10. Балакина Г.Ф. Проблемы определения эффективности реализации стратегии развития региона // Региональная экономика: теория и практика. 2017. T. 15, № 8. C. 1428-1441. URL: https://elibrary.ru/ item.asp?id=29823415. DOI:10.24891/re.15.8.1428.

11. Гагарина Г.Ю., Дзюба Е.И., Губарев Р.В., Файзуллин Ф.С. Прогнозирование социально-экономического развития российских регионов // Экономика региона. 2017. T. 13, вып. 4. С. 1080-1094. URL: https:// elibrary.ru/item.asp?id=30783287. DOI: 10.17059/2017-4-9. 
12. Урасова А.А., Зубарев Н.Ю., Мухин М.А. Особенности оценки социально-экономического развития сельских территорий в современных условиях // Вестник Воронежского государственного аграрного университета. 2018. № 1(56). С. 205-212. URL: https://elibrary.ru/item. asp?id=35233678. DOI: 10.17238/issn2071-2243.2018.1.205.

13. Губанова Е.С., Клещ В.С. Методика оценки неравномерности социально-экономического развития региона // Проблемы развития территории. 2018. № 6 (98). C. 30-41. URL: https://elibrary.ru/item. asp?id=36499950. DOI: 10.15838/ptd.2018.6.98.2.

14. Захарчук Е.А. Пространственная структура формирования добавленной стоимости арктических территорий // Экономика региона. 2019. Т. 15,вып. 2. С. 391-408. URL: https://elibrary.ru/item. asp?id=38558081. DOI: 10.17059/2019-2-7.

15.Захарчук Е.А., Заварзина Л.С. Теоретические подходы к формированию доходов муниципальных образований: межбюджетные отношения и Система национальных счетов // Вестник Уральского института экономики, управления и права. 2015. № 3 (32). С. 54-65. URL: https://elibrary.ru/item.asp?id=25291723.

16.Захарчук Е.А. Финансовая устойчивость территорий: теория, методология, практика // Экономика. Налоги. Право. 2009. № 6. С. 43-54. URL: https://elibrary.ru/item.asp?id=12997664.

17.Захарчук Е.А. Экономическая устойчивость и теория катастроф: точки соприкосновения: Препринт. Екатеринбург: - Сер. Научные доклады / Российская акад. наук, Уральское отд-ние, Ин-т экономики. 2006. 68c. URL: https://elibrary.ru/item.asp?id=20042545.

18.Захарчук Е.А., Пасынков А.Ф. Оценка финансовой устойчивости территорий на основе показателей системы территориальных счетов // Журнал экономической теории. 2018. T.15.№ 1. С. 57-65. URL: https://elibrary.ru/item.asp?id=32673386.

19.Захарчук Е.А., Пасынков А.Ф., Трифонова П.С. Роль бюджетно-налоговой политики в формировании финансовых балансов регионов на примере Уральского федерального округа // Экономика. Налоги. Право. 2020. Т. 13. № 1. С. 86-98. URL: https://elibrary.ru/item. asp?id=42671087. DOI: 10.26794/1999-849X-2020-13-1-86-98 
20. Татаркин Д.А., Сидорова Е.Н., Трынов А.В. Моделирование структурных изменений экономики региона на основе матрицы финансовых потоков // Экономические и социальные перемены: факты, тенденции, прогноз. 2017. Т. 10. № 1. С. 218-234. URL: https://elibrary. $\mathrm{ru} /$ item.asp?id=28807541. DOI: 10.15838/esc.2017.1.49.12

21.SNA - System of National Accounts 2008, released by the United Nations, the European Commission, the International Monetary Fund, the Organisation for Economic Cooperation and Development, and the World Bank, New York, 2009

\section{References}

1. Zelyak E.F., Boldyreva A.M. Otsenka znachimosti pokazateley sotsial'no-ekonomicheskogo razvitiya regionov RF [Assessment of the significance of indicators of socio-economic development of regions of the Russian Federation]. Ekonomicheskaya nauka sovremennoy Rossii, 2003, № 4, pp. 48-53. URL: https://elibrary.ru/item.asp?id=9614460.

2. Tsomartova, L. V. Metodika otsenki urovnya sotsialno-ekonomicheskogo razvitiya regiona I modeli upravleniya ekonomicheskim razvitiem regiona [Estimation methods of social and economic region development level and the management models of its economic development]. Vestnik Severo-Osetinskogo Gosudarstvennogo Universiteta imeni Kosta Levanovicha Khetagurova, 2010, №3, pp. 128-135. URL: https://elibrary.ru/item.asp?id=15237342.

3. Skotarenko O.V. Rossiyskiy opyt otsenki urovnya sotsial'no-ekonomicheskogo razvitiya regiona [The Russian experience of evaluation of the level of socio-economic development of the region]. Fundamental'nye issledovaniya, 2013, №1, pp. 823-829. URL: https://elibrary.ru/item.asp?id=18771787.

4. Menshchikova V. I., Cherkashnev R. Yu. Metodicheskiy instrumentariy otsenki rezul'tativnosti sotsial'no-ekonomicheskoy politiki razvitiya regionov [Methodical tools of the assessment of productivity of social and economic policy of development of regions]. Sotsial'no-ekonomicheskie yavleniya i protsessy, 2013, №3(049), pp. 110-116. URL: https://elibrary. $\mathrm{ru} /$ item.asp? $\mathrm{id}=19084048$.

5. Glushakova O.V., Vaysberg Ya.A. Sotsial'noe i ekonomicheskoe prostranstvo regionov: kontseptual'nye podkhody $\mathrm{k}$ izmereniyu i metodika otsenki (na 
primere regionov Sibirskogo federal'nogo okruga) [Social and Economic Space of Regions: Conceptual Approaches to Measurement and Assessment Methods (on the Example of Regions of the Siberian Federal District)]. Vestnik tomskogo gosudarstvennogo universiteta. Ekonomika, 2013, №2(22), pp. 159-173. URL: https://elibrary.ru/item.asp?id=19371507.

6. Shabunova A. A., Gruzdeva M. A. Razvitie regionov Rossiyskoy Federatsii: integral'naya metodika kak instrument otsenki [Development of the regions of the russian federation: integral technique as an evaluation tool]. Regional'naya ekonomika: teoriya i praktika, 2016, №1, pp. 100-112. URL: https://elibrary.ru/item.asp?id=25239178.

7. Kislitsyna V. V., Cheglakova L. S., Karaulov V. M., Chikisheva A. N. Formation of the integrated approach to the assessment of socio-economic development of regions. Ekonomika regiona, 2017, 13(2), pp. 369-380. URL: https://elibrary.ru/item.asp?id=29364283. DOI:10.17059/2017-2-4

8. Kalinina A. E., Sokolov A. F. Effektivnost' upravleniya regionom v usloviyakh modernizatsionnykh preobrazovaniy rossiyskoy ekonomiki i razvitiya informatizatsii [Efficiency of regional management in the context of modernization transformations of the Russian economy and the development of informatization]. Ekonomika regiona, 2013, № 3. pp. 112-121. URL: https://elibrary.ru/item.asp?id=20285472. DOI: 10.17059/2013-3-9.

9. Nizhegorodtsev R. M., Piskun E. I., Kudrevich V. V. Prognozirovanie pokazateley sotsial'no-ekonomicheskogo razvitiya regiona [The Forecasting of Regional Social and Economic Development]. Ekonomika regiona, 2017, 13(1), pp. 38-48. URL: https://elibrary.ru/item.asp?id=28807316. DOI: $10.17059 / 2017-1-4$.

10. Balakina G.F. Problemy opredeleniya effektivnosti realizatsii strategii razvitiya regiona [Regional development strategy: Issues of determining the realization effectiveness]. Regional Economics: Theory and Practice, 2017, vol. 15, iss. 8, pp. 1428-1441. URL: https://elibrary.ru/item. asp?id=29823415. DOI:10.24891/re.15.8.1428.

11. Gagarina, G. Y., Dzyuba, E. I., Gubarev, R. V. \& Fayzullin, F. S. Prognozirovanie sotsial'no-ekonomicheskogo razvitiya rossiyskikh regionov [Forecasting of Socio-Economic Development of the Russian Regions]. Ekonomika regiona, 2017, vol. 13(4), pp. 1080-10949. URL: https://elibrary.ru/item.asp?id=30783287. DOI: 10.17059/2017-4-9. 
12. Urasova A. A., Zubarev N. Yu., Mikhin M.A. Osobennosti otsenki sotsial'no-ekonomicheskogo razvitiya sel'skikh territoriy v sovremennykh usloviyakh [The peculiarities of assessing the social and economic development of rural territories in modern conditions]. Vestnik Voronezhskogo gosudarstvennogo agrarnogo universiteta, 2018, № 1(56), pp. 205212. URL: https://elibrary.ru/item.asp?id=35233678. DOI: $10.17238 /$ issn2071-2243.2018.1.205

13. Gubanova E.S., Kleshch V.S. Metodika otsenki neravnomernosti sotsial'no-ekonomicheskogo razvitiya regiona [Methods to Evaluate Uneven Socio-Economic Development of a Region. Problems of Territory's Development]. Problemy razvitiya territorii, 2018, no. 6 (98), pp. 30-41. URL: https://elibrary.ru/item.asp?id=36499950. DOI: 10.15838/ptd.2018.6.98.2

14. Zakharchuk, E. A. Spatial Structure of the Formation of Value Added in the Arctic Territories. Ekonomika regiona, 2019, no.15(2), pp. 391-408. URL: https://elibrary.ru/item.asp?id=38558081. DOI: 10.17059/2019-2-7.

15. Zakharchuk E. A., Zavarzina L.S. Teoreticheskie podkhody k formirovaniyu dokhodov munitsipal'nykh obrazovaniy: mezhbyudzhetnye otnosheniya i Sistema natsional'nykh schetov [Theoretical approaches to the formation of income of municipalities: interbudgetary relations and the System of National Accounts]. Vestnik Ural'skogo instituta ekonomiki, upravleniya i prava, 2015, № 3 (32), pp. 54-65. URL: https://elibrary.ru/item.asp?id=25291723.

16.Zakharchuk E.A. Finansovaya ustoychivost' territoriy: teoriya, metodologiya, praktika [Financial sustainability of territories: theory, methodology, practice]. Ekonomika. Nalogi. Pravo, 2009, № 6, pp. 43-54. URL: https://elibrary.ru/item.asp?id=12997664.

17.Zakharchuk E.A. Ekonomicheskaya ustoychivost' i teoriya katastrof: tochki soprikosnoveniya: Preprint [Economic sustainability and disaster theory: common ground: Preprint]. Ekaterinburg: Rossiyskaya akad. nauk, Ural'skoe otd-nie, In-t ekonomiki, 2006. 68p. URL: https:/elibrary. $\mathrm{ru} / \mathrm{item}$.asp? $\mathrm{id}=20042545$.

18. Zakharchuk E.A., Pasynkov A.F. Otsenka finansovoy ustoychivosti territoriy na osnove pokazateley sistemy territorial'nykh schetov [Assessment of the financial stability of territories based on indicators of the system of territorial accounts]. Zhurnal ekonomicheskoy teorii, 2018, vol. 15.№ 1, pp. 57-65. URL: https://elibrary.ru/item.asp?id=32673386. 
19. Zakharchuk E.A., Pasynkov A.F., Trifonova P.S. Rol' byudzhetno-nalogovoy politiki $v$ formirovanii finansovykh balansov regionov na primere Ural'skogo federal'nogo okruga [The role of fiscal policy in the formation of financial balances of regions on the example of the Ural Federal District]. Ekonomika. Nalogi. Pravo, 2020, vol. 13. № 1, pp. 86-98. URL: https://elibrary.ru/ item.asp?id=42671087. DOI: 10.26794/1999-849X-2020-13-1-86-98

20. Tatarkin D.A., Sidorova E.N., Trynov A.V. Simulation of structural changes in the regions economy based on the matrix of financial flows. Economic and Social Changes: Facts, Trends, Forecast. 2017, T. 10. № 1, pp. 218-234. URL: https://elibrary.ru/item.asp?id=28807541. DOI: $10.15838 /$ esc.2017.1.49.12

21. SNA - System of National Accounts 2008, released by the United Nations, the European Commission, the International Monetary Fund, the Organisation for Economic Cooperation and Development, and the World Bank, New York, 2009.

\section{ДАННЫЕ ОБ АВТОРЕ}

Пасынков Алексей Федорович, кандидат экономических наук, доцент; заведующий сектором финансового развития территорий ФГБУН Институт экономики УрО РАН

ул. Московская, 29, г. Екатеринбург, 620014, Российская Федерация

monografia@mail.ru

\section{DATA ABOUT THE AUTHOR}

Pasynkov Aleksey Fyodorovich, Candidate of Economic Sciences, Associate Professor, Head of the Sector of Strategic and Financial Institute of Economics of the Ural Branch of the Russian Academy of Sciences 29, Moskovskaya str., Yekaterinburg, 620014, Russian Federation monografia@mail.ru

SPIN-code: 7584-0350

ORCID: 0000-0001-5186-4130

ResearcherID: L-7150-2017

Scopus Author ID: 56736526700 